\title{
Packaging Design and the Changing Needs of End Consumers
}

\author{
Ming Li ${ }^{*}$ \\ Guangzhou Hushang College, Zengcheng 511300, China \\ *Corresponding author: Ming Li, louman123123@163.com
}

\begin{abstract}
With the rapid development of China's economy, the society has entered the era of big data intelligence, leading to tremendous changes in people's shopping methods. From the original way of shopping via traditional channels from street vendors and farmer's markets to shopping via WeChat, Douyin, Taobao, Pinduoduo, and other digital e-commerce channels, online shopping has become the norm and an integral part of people's life in the post-pandemic era. The shift from traditional offline shopping to online shopping calls for a change in design thinking, integrating food packaging design, consumer needs, and brand stories, reflecting individual characters and regional cultures, as well as incorporating traditional Chinese style and cultural elements.
\end{abstract}

Keywords: End consumers; Food packaging design; Design thinking

Publication date: December 2021; Online publication: December 31, 2021

\section{Introduction}

Living in a globalized digital world driven by big data, online shopping has become the major trend, in particular, amidst the post-pandemic era. Therefore, packaging design should also be updated accordingly to reflect the demands of online shopping. While food safety is at the heart of food packaging in preventing food spoilage as they are transported from factories to consumers, designers should also pay more attention to how packaging delivers fashionable, charming, and eye-catching effects; packaging materials should be environmental-friendly and sustainable. Brand stories, interactivity, good-user experience, and the potential to gain popularity on social media are also important. This paper attempts to discuss how packaging design reflects the changing needs of end consumers, consumption structures, as well as social and economic development.

\section{Food packaging design and its market demand in response to the changing needs of end consumers}

In the digital era with fast and open economic growth, people adapt quickly to new things. Foreign cultures have had an impact on food packaging, with some businesses struggling to meet changing market demands ${ }^{[1]}$. Companies are polarized under the impact of such fundamental consumption structure shifts. Some producers who are capable of meeting the changing demands of consumers and markets are able to make adjustments accordingly, whereas others who have failed to keep up to date are phased out by the market. The pandemic has significantly boosted online consumption. Offline store transactions have shrunk sharply, with online shopping platforms quickly emerging, creating multiple new trends. According to Tianyancha's 2020 E-commerce Report, live streaming shopping, "buy online ship to home," and community group purchases have become the primary shopping methods ${ }^{[2]}$. With the changes in consumer needs and consumer structures brought about by e-commerce, there is a greater demand for packaging to reflect the Chinese culture and its characteristics. Consumers are no longer satisfied with packagings that only wrap 
up food; instead, they expect to see attractive packagings that reflect brand stories, show their high tastes, embody traditional Chinese fashionable elements, and meet their needs to post on social media. Therefore, food packaging should not only keep food safe but also embody cultural elements and meet the needs of social and economic development ${ }^{[3]}$.

\section{Visual arts for food packaging in response to the changing needs of end consumers}

\subsection{Revival of Guochao - the Chinese traditional style and culture}

Affected by the pandemic, the year-on-year increase in the number of Chinese brand products, number of orders, and order volume was significantly higher than that of imported brands, reaching over $30 \%$ in the first quarter of 2020. In the first half of this year, $80 \%$ of the brands with over 100 million yuan of sales revenue on JD.com are Chinese brands ${ }^{[4]}$. The trend to revive Guochao powered by "made in China" campaign has brought about national confidence. In order to integrate more Chinese culture elements into food packaging, it is not only imperative to pay attention to conveying the artistic values, but also showcasing the five thousand years of Chinese culture. Integrating traditional Chinese elements into food packaging will allow consumers to savor the amazing Chinese culture as well as create ideological and emotional resonance between designers and consumers ${ }^{[5]}$. The artistic values must be created based on the diverse nature of food. In order to create resonance using packaging materials, images, and texts, one should fully employ the brand culture and regional characters to connect with the consumers' ideologies ${ }^{[6]}$. As technologies and productivity are advancing rapidly nowadays, values, ideologies, and national consciousness are also on the rise. Therefore, incorporating cultural elements would become a prevailing trend in food packaging and so is the trend for packaging with Guochao.

Figure 1 shows a mooncake gift box designed for the Mid-Autumn Festival, with the theme of Foshan Lion Dance. The traditional Chinese decorative pattern is combined with the image of dancing lions. The illustration depicts the auspicious lion, dancing in front of the ancestral temple of Foshan's iconic building. It highlights the important status of the dancing lion in Lingnan folk culture, as they appear frequently on festive occasions. While displaying the folk affection for lions dancing, it also combines fashion with traditional culture.

As for the packaging structure, eight small cubes (small packages), representing the flavors of the fruit mooncakes (e.g., green for cantaloupe, red for strawberry), form a large cube. The combination also conveys the auspicious message of a wonderful reunion during the Mid-Autumn Festival. According to big data research findings, China's consumers are among those from the younger age group, and mooncakes are mainly bought to be given as Mid-Autumn Festival gifts. As the consumers tend to be of the younger age group, food packaging design should also function as means for social networking. Unique food packaging must be designed to keep up the trend of the revival of traditional Chinese fashion. 

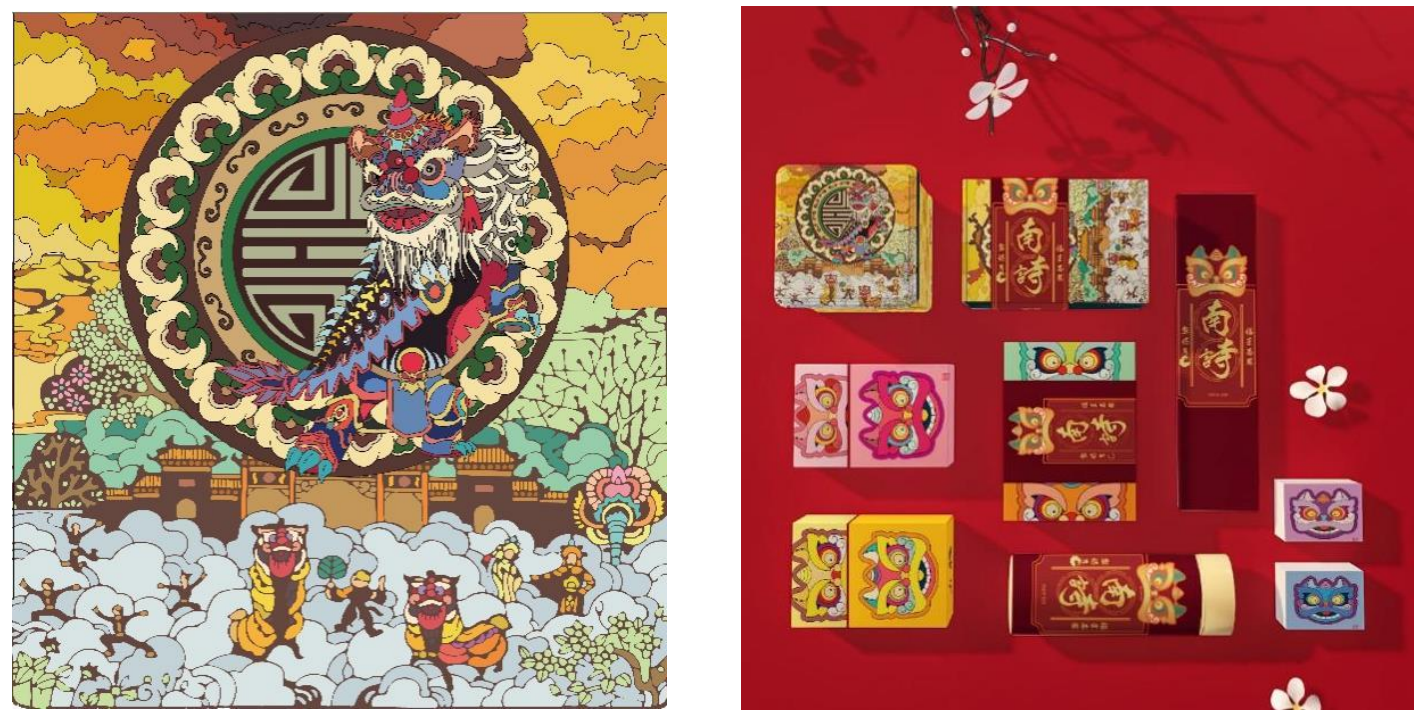

Figure 1. Mooncake packaging design (Source: Packaging design by Liang Jiajie)

\subsection{Interesting illustrations}

Packaging design conveys specific information to the targeted consumers through visual art expressions and have a certain potential impact on them. While the excellence of a company is not determined by the visual art design on its packaging, it will, however, strike the first impression on consumers. Therefore, packaging must be a priority because good packaging helps establish a good brand image among consumers and increase their desires to purchase the products, thereby contributing to higher profits.

Figure 2 shows a local food product designed for Shanwei City, Guangdong Province. It is a snack popular in eastern Guangdong. This snack is made out of a mixture of lard, flour, and sugar. In the 1970s and 1980s, it was the favorite snack among children. Therefore, having this snack enables one to recall wonderful childhood memories. Both illustrations are based on pigs. The background of the first illustration is the sunset at sea, depicting a herd of small pigs fighting for the candy. The whole illustration brings one back to childhood, where one person runs after another to fight for the candy. With the Red Palace Plaza of Haifeng County set in the background, the second illustration shows two pigs holding candies, welcoming people to the local tourist attraction and to try the lard candy. The vivid cartoon illustrations attempt to bring one back to childhood, where the pigs, the beach, and the Red Palace Plaza, along with the iconic sites remind people of a peaceful and beautiful life.
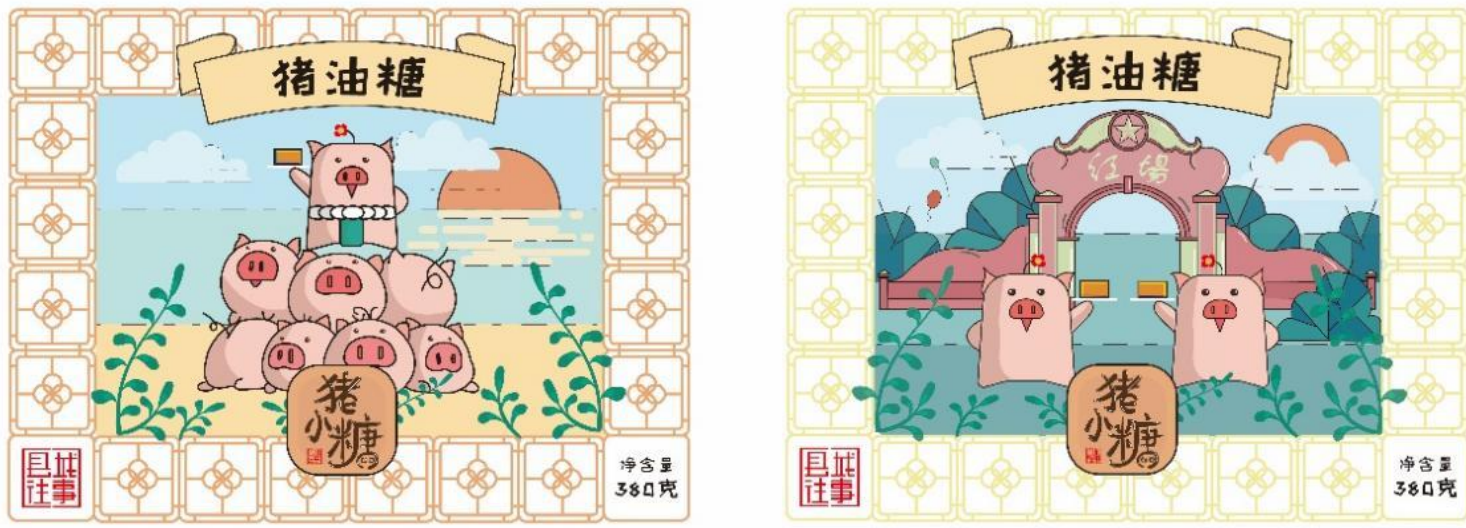

Figure 2. Lard candy packaging design (Source: Packaging design by An Yukang) 


\section{Interactivity of food packaging in response to the changing needs of end consumers}

\subsection{User experience}

Digital life has disrupted the traditional way of life, and food packaging should go further than satisfying the basic needs as food wrappers. Innovative packaging that does not only stimulate one's sense of sight, smell, and touch, but also create interactive experiences with all senses should be encouraged. Depending on the materials, there are five types of food packaging: paper, plastic, wood, glass, and metal. Marketing surveys should be conducted for different products. After analyzing the data from consumers psychology perspective and market demand, food packaging should be developed in such a way that it interacts with one's touch and visual senses.

For example, in Figure 3, the packaging of Oreo cookies in a music box. Made into a music box, the cookies reflect three things: (1) customized Oreo cookies with the theme of "Everyone has their own favorite"; (2) auditory senses are engaged as the music box changes its songs as consumers bite the cookie each time; the fact that songs are played randomly underscores its creativity; (3) it provides an interactive augmented reality (AR) experience, where consumers would not only enjoy the tasteful cookies, but also its playful characteristics. The Oreo music boxes were sold out online quickly, raising its sales and brand popularity among consumers.
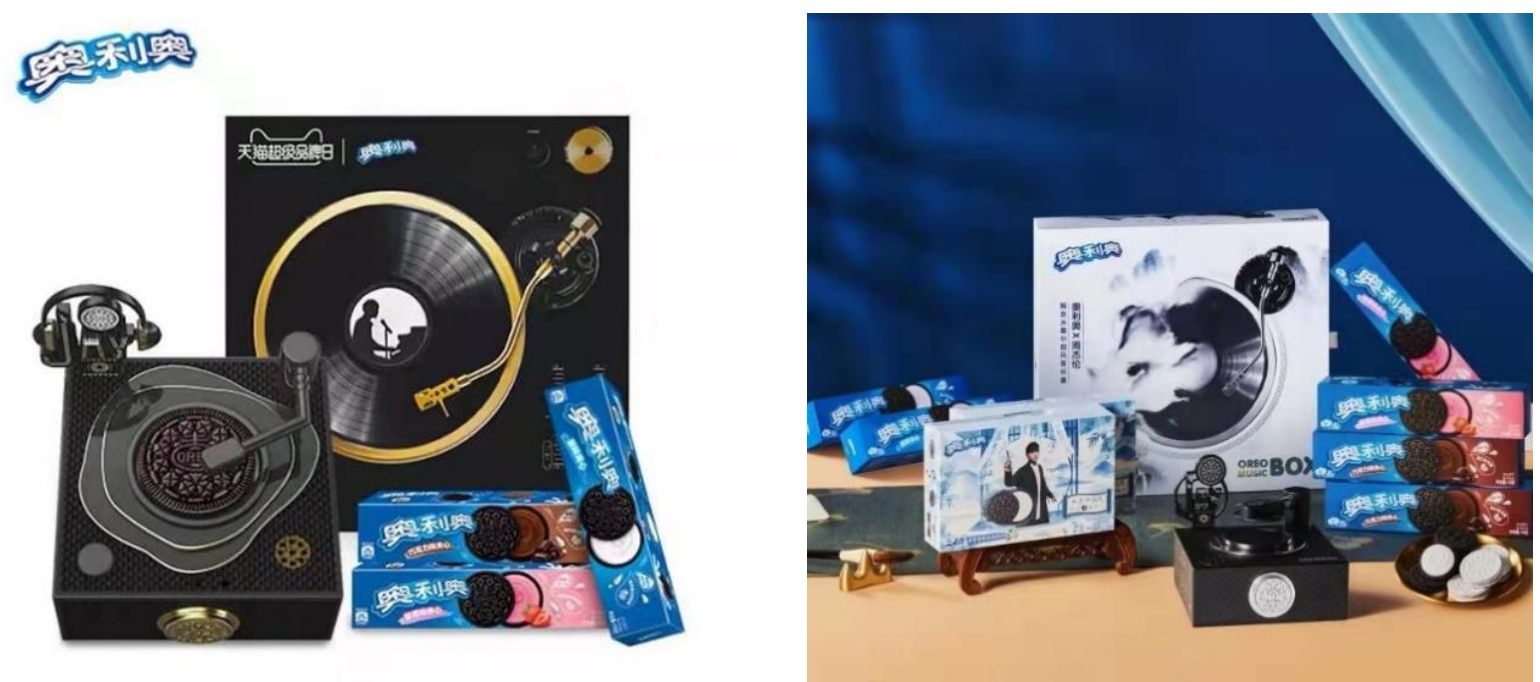

Figure 3. Oreo music box (Source: JD.com)

\subsection{Story-telling}

Food packaging should tell stories. At first glance of the packaging, it should be able to resonate with and touch the soul of consumers. Designers can integrate product features with the times to bring consumers back to the good old days and create exciting emotions to capture their heart so that they will be tempted to purchase the products, which in turn helps to generate profit for businesses. Figure 4 is an example of Shanglinyuan, a tea brand. The series of packaging illustrates tea picking, roasting, and drying, vividly depicting how tea is made through careful selection and dedicated cultivation. Consumers can easily connect the illustrations with the refined, humanistic traditional Chinese tea culture. 

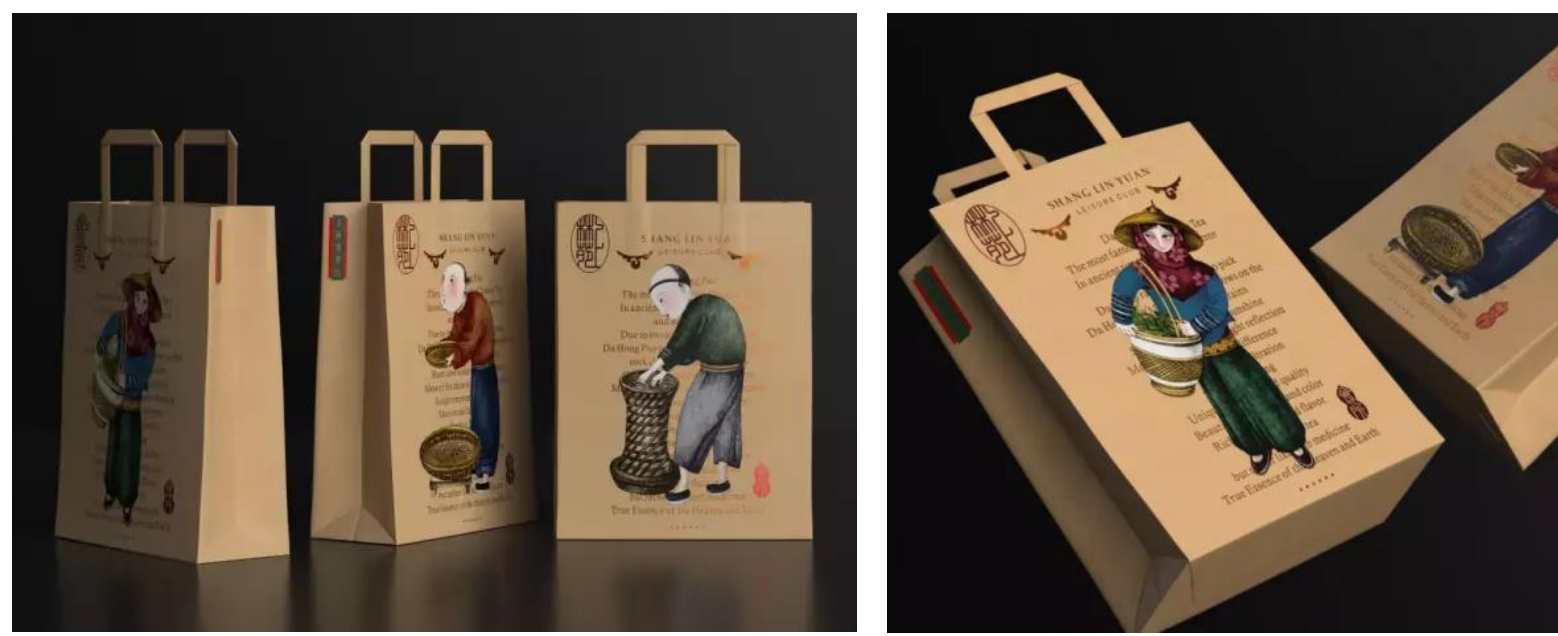

Figure 4. Shanglinyuan tea packaging design (Source: WeChat public account)

\subsection{Greater loyalty}

In recent years, with the rise of express delivery services and the rapid development of e-commerce, food sales have increased in online sales, thus giving more choices to consumers. Faced with a large number of products, consumers often feel confused. Since consumers do not have access to the product itself, the choice of product quality has shifted to the product brand. More companies are paying attention to shaping their brands on the internet. For example, brands such as Taotaoju and Xuanma Egg Yolk Pastry have taken advantage of their product quality and taste to build a sense of trust among consumers.

Smart electronic products manage people's health digitally. For example, consumers who wear smart electronic products of a certain brand will upload their health data to the cloud, and they can then choose suitable products based on their health data. This could mean that brands should work to meet the consumers' requirements, but also reflect on consumers' greater reliance on their products.

\section{The sustainable development of food packaging design materials in response to the changing needs of end consumers}

With the rapid development of technology and economy, express delivery services have made people's life more convenient. However, they have produced a large number of packaging waste, causing great harm to the environment. As people become more aware of ecological and environmental issues, green packaging and environmental protection are high on the agenda for governments and packaging industries all over the world. Therefore, to raise environmental protection awareness among the public, the modern food packaging design industry in China should be committed to green development. Food packaging must adopt targeted methods to meet recycling and environmental protection objectives ${ }^{[7]}$.

There are two ways for green and environmental-friendly food packaging design: the first is to choose environmental-friendly packaging materials; the second is to disseminate environmental protection ideas through the packaging design where texts, pictures, and other means that promote environmental protection are inscribed on the packaging. Consumers will be able to read such information whenever they unpack the products.

\section{Conclusion}

With the advent of the big data era featuring "Internet Plus" and digital intelligence, the way people shop has changed. Consumers are able to browse and gain much greater information about products in a short span of time. With this in mind, how then can food packaging design capture the hearts of consumers and 
respond to the needs of the market? Only when designers put themselves into the shoes of consumers and understand better what the market needs can they deliver unique and trendy food packages.

\section{Funding}

This study was supported by the Guangdong Province Education Science Planning Project - Research on Tourism Cultural and Creative Design in the "Internet +" Era (Number: 2018GXJK276) and one of the first-class course projects (2021) of Guangzhou Hushang College - Packaging Design (HS2021YLKC09).

\section{Disclosure statement}

The author declares that there is no conflict of interest.

\section{References}

[1] $\mathrm{Xu} \mathrm{W,} \mathrm{2020,} \mathrm{The} \mathrm{Creative} \mathrm{Use} \mathrm{of} \mathrm{Visual} \mathrm{Communication} \mathrm{in} \mathrm{Food} \mathrm{Packaging} \mathrm{Design} \mathrm{-} \mathrm{Comment} \mathrm{on}$ "Food Packaging Design". China Brewing, 39(04): 229.

[2] Xinhua News, 2020, [Study Intelligence Observation] Big Data Tells You These New Trends in 2020 Internet Consumption. XINHUANET.com. http://www.xinhuanet.com/finance/2020-12/16/c_112686 7773.htm

[3] Gu Q, 2019, Visual Communication Design Inspired by "Playing Cards". Packaging Engineering, 40(10): 73-77.

[4] The Xinhua News Agency New Media, 2020, Looking at JD Big Data's Online Consumption Trends in 2020. Baidu. https://baijiahao.baidu.com/s?id=1687486099140114360\&wfr=spider\&for=pc

[5] Yang D, 2018, Research on the Visual Communication Design Concept of Dyeing and Finishing Industry Journals in the New Media Network Era. Dyeing and Finishing Technology, 40(01): 15-16, 36.

[6] Wang W, 2020, The Application of Traditional Visual Symbols in Food Packaging Design. Food Research and Development, 41(20): 233.

[7] Shao C, 2020, Research on Agricultural Product Packaging Design Style Under the Concept of Green Environmental Protection - Comment on "Food Packaging Creative Design". Chinese Melon, 33(05): 95-96. 